\title{
Editorial
}

\section{Medical research in the Rhondda valleys}

The South Wales mining valleys have made a major contribution to medical research over the last 60 years. In 1936, the Medical Research Council (MRC) was asked by the Home Office and Mines Department to investigate the problem of pulmonary disease among coalminers, with particular reference to conditions in the South Wales coalfield. At that time there were over 200000 men employed at 250 pits in the Welsh deep mine coal industry. Today there are less than 2000 men employed in the now mainly opencast Welsh coal mining industry, and only one deep pit is worked. The problem of coal workers' pneumoconiosis ('black' lung) was extensive. Between 1931 and 1948 over 22000 British miners were required to leave their work because they had contracted pneumoconiosis, and $85 \%$ of them were living in the small mountainous coalfield of South Wales. ${ }^{1}$ The high incidence of disease in the area had been found to be related to the rank of coal mined, with the prevalence of disease being highest in the anthracite (high rank) mines, lower in steam coal mines and still lower in bituminous mines. ${ }^{2}$ Many factors related to dust diseases, dust measurement and dust control were poorly understood, and in 1945 the MRC established the Pneumoconiosis Unit at Llandough Hospital, Penarth, to research these issues. The Unit, which was one of the largest MRC establishments, remained active until 1985, and in 1960 produced an offshoot, the MRC Epidemiology Unit (South Wales) under the direction of Dr Archie Cochrane, which continued research until March 1999. These two Units contributed to many aspects of medicine and some of their work on lung disease, blood pressure, anaemia, glaucoma and medical screening will be briefly reviewed.

Major lessons emerge when each subject is examined. The research teams had to establish a simple reproducible, valid measure of the condition for large scale survey work, often challenging current clinical thinking and the value of existing tests, measure the prevalence of the condition in the general population, consider whether medical treatments could influence the prognosis, and often undertake long term follow-up studies to see whether the condition affected survival.

Archie Cochrane (figure 1), who worked at the MRC Units between 1949 and 1986, was a medical scientist who thought widely about the effectiveness and efficiency of modern medical practice, ${ }^{34}$ and sought a more scientific approach to medical research, particularly encouraging the use of randomised controlled trials. His call for medicine to be evidence based was the inspiration for the later establishment, primarily by Iain Chalmers and colleagues, of the Cochrane Collaboration.

\section{Lung disease}

The first director of the MRC Pneumoconiosis Research Unit was Dr Charles Fletcher. To study pneumoconiosis he realised that a consistent radiological grading system for this condition should be established to reduce observer error, to accurately measure the prevalence of the disease, and to assess progression over time ${ }^{6}$ His team worked with researchers in the US and developed a chest X-ray classification that was later adopted by the International Labour Office.
Large surveys of mining communities in the Rhondda Fach (little Rhondda) were undertaken in 1950 and 1953 to establish the prevalence of pneumoconiosis and tuberculosis (figure 2). ${ }^{7}$ With the post-war introduction of

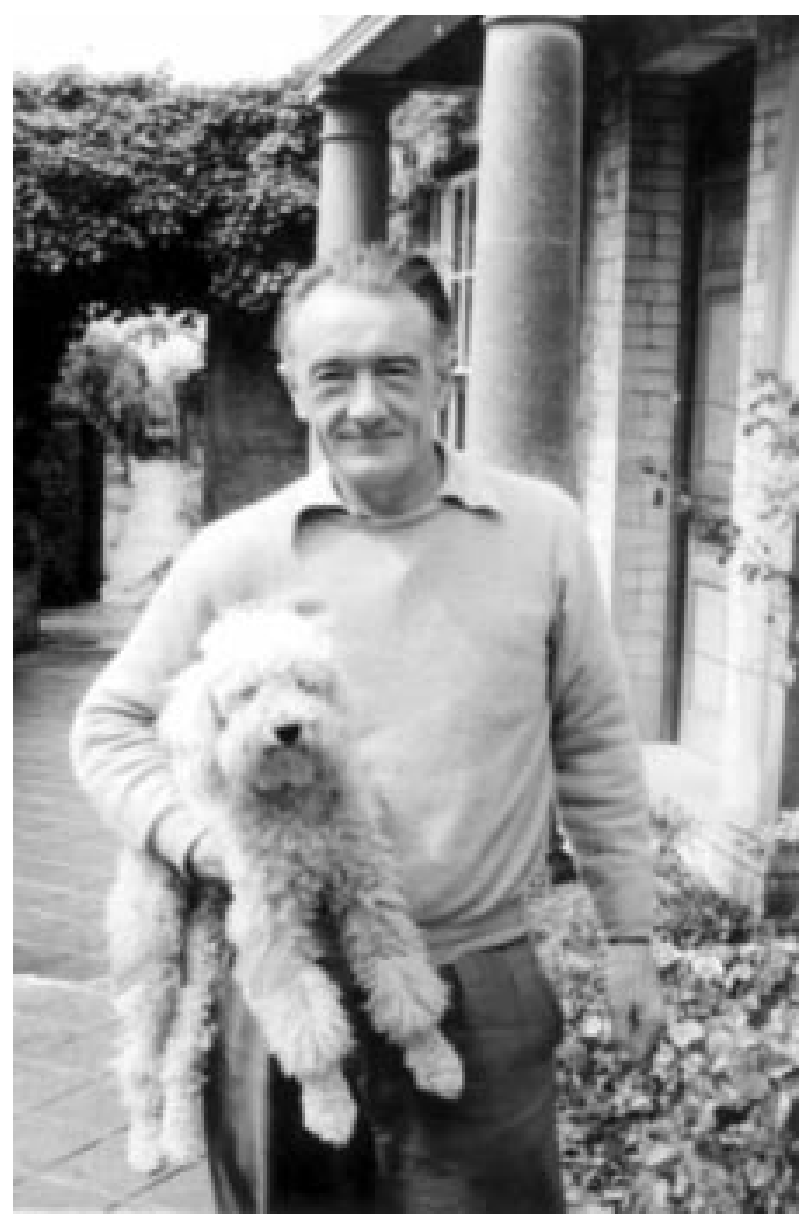

Figure 1 Archie Cochrane outside his home, ca 1956

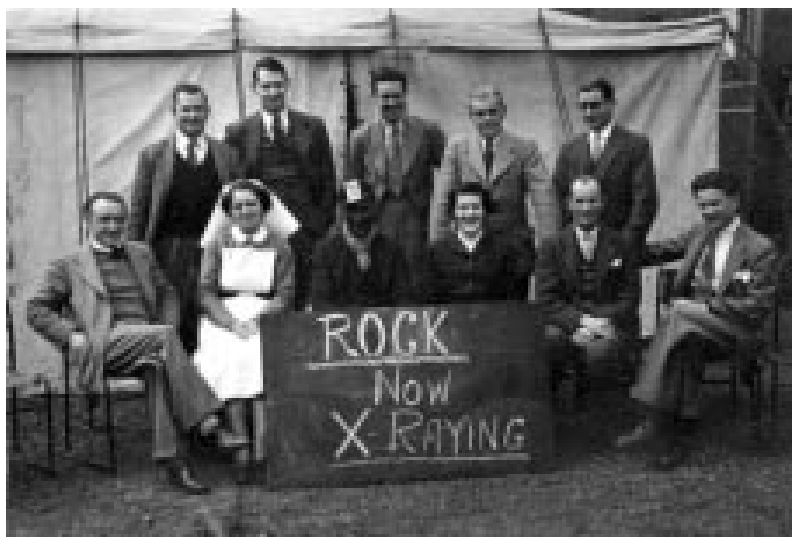

Figure 2 The MRC Pneumoconiosis Research Unit team at the Rock Colliery in 1953. AL Cochrane is seated far left 
streptomycin and BCG immunisation, the incidence of tuberculosis declined steeply, and better dust control in the mines saw a reduction in new pneumoconiosis cases. The initial surveys suggested that simple pneumoconiosis did not significantly affect physical function, but advanced (complicated) pneumoconiosis could be very disabling, especially progressive massive fibrosis. Cochrane and co-workers followed up the Rhondda population on subsequent occasions - after six, 20 and 30 years. ${ }^{8}$ The presence of simple pneumoconiosis did not appear, in the long term, to markedly reduce survival but complicated pneumoconiosis, particularly progressive massive fibrosis, was associated with a much higher death rate. The Rhondda data were also used to assess other aspects of chest disease, and showed that air flow obstruction and mucus hypersecretion were largely independent of each other, with the risk of later death being strongly related to the initial degree of air flow obstruction. ${ }^{9}$ Despite much research no real answer was found to the question of why some men developed progressive massive fibrosis and others did not.

The Pneumoconiosis Research Unit research programme contributed to a variety of interesting projects. Dr John Cotes, a respiratory physiologist, advised the British Mount Everest expedition on oxygen equipment prior to their successful ascent, ${ }^{10}$ and also developed a portable apparatus for home oxygen therapy for those with advanced lung disease. ${ }^{11}$

The existence of Caplan's syndrome, a nodular fibrosis of the lungs associated with rheumatoid arthritis, was confirmed by using Rhondda survey data. ${ }^{12}$ In 1960 Wright, who had recently moved to the National Institute for Medical Research, London, and McKerrow described a simple peak flow meter ${ }^{13}$ which was the forerunner of the devices now commonly used world-wide for the monitoring of respiratory function, especially by asthmatics.

The questionnaire measurement of respiratory disease, although not an exciting research topic, is important, and Fletcher, who moved to the Postgraduate Medical School in 1952, maintained links with the Pneumoconiosis Research Unit and was instrumental in devising the MRC Chronic Bronchitis Questionnaire. ${ }^{14} \mathrm{He}$ achieved fame in the 1950 s as the first television doctor, presenting 'Your life in their hands', and was a founder of the pressure group ASH (Action on Smoking and Health), having encouraged the Royal College of Physicians to produce a major report on the subject.

\section{Hypertension}

Dr Bill Miall, who first worked with Cochrane in a Salonica prisoner of war hospital, ${ }^{4}$ developed the research programme on hypertension. Personally examining 1228 people in the Rhondda (and 1640 in the Vale of Glamorgan) he produced data, analysed by Peter Oldham, a statistician trained by Sir Austin Bradford Hill, which showed that blood pressure was a physical characteristic analogous with, for example, obesity or height. ${ }^{15-17}$ It was a continuous variable, probably with polygenic inheritance, and with no natural boundary separating normal from abnormal. Forty years later such a concept of hypertension is accepted wisdom, but for a decade from the mid-1950s there was a major scientific debate between Sir George Pickering and Lord Platt about whether blood pressure was unimodally or bimodally distributed. The evidence from the Rhondda studies supported the former view and Pickering won the debate, although recent genetic research is again interested in population subgroups for whom a genetic tendency to hypertension may be important. ${ }^{18}$ Miall later moved to Jamaica to study blood pressure and subsequently returned to Northwick Park where his wide experience enabled him to play a major role in establishing and co-ordinating the large MRC national studies on the treatment of mild hypertension.

\section{Anaemia}

Early surveys in the Rhondda examined the normal range of haemoglobin levels in the community. Again, the measurement technique had to be validated..$^{19}$ Elwood and colleagues examined 900 non-pregnant women in the Rhondda Fawr (big Rhondda) and found 10\% with haemoglobin levels below $12 \mathrm{~g} / \mathrm{dl}$ blood but few had symptoms and none had serious underlying pathology. ${ }^{20}$ Symptoms were found to occur only at levels below $8 \mathrm{~g} / \mathrm{dl}$ blood. These observations raised the general issue of whether iron tablets were being unnecessarily prescribed in Britain for symptoms such as tiredness when there was no objective evidence that anaemia was the cause or that iron supplements helped. ${ }^{20}$ A large study on supplementing bread with iron showed it to be a poor method of increasing iron levels in the population. ${ }^{21}$ The various Epidemiology Unit studies of anaemia in women between 1964 and 1969 involved 18470 women. Follow-up over 3 years found a small increase in the mortality rate for anaemic women and a much increased mortality rate for women with a high $(>46 \%)$ haematocrit. ${ }^{22}$

\section{Glaucoma}

The population of the Rhondda offered a young Australian ophthalmologist, Fred Hollows, and colleagues from the Cardiff Royal Infirmary, the opportunity to examine the prevalence of raised intra-ocular pressure in the community. In the summer of 1963 they measured the intra-ocular pressures of 4246 persons aged 40-75 years. Important papers on sources of variation in tonometry ${ }^{23}$ and on the prevalence of glaucoma, including low-tension glaucoma, were produced. ${ }^{24}$ The latter paper is still commonly quoted in major reviews of glaucoma. Hollows later wrote that without his experiences in Wales he would not have achieved what he did working on the National Trachoma and Eye Program among Australian aborigines. ${ }^{25}$ For such work Hollows, who had been called 'the wild colonial boy of Australian surgery' received in 1990 both the Australian Human Rights Medal and Australian of the Year award, and, in 1993, a state funeral. ${ }^{25}$

\section{Medical screening}

The large medical surveys in the Rhondda gave Cochrane and Elwood exceptional experience in having to define a medical condition, measure it simply and reproducibly, and consider its long-term significance. As early as 1951, Cochrane and colleagues recommended that a system of periodic chest X-rays for coal miners should be introduced, so that men with early changes could be removed from exposure and avoid developing progressive massive fibrosis. ${ }^{26}$ During the 1960 s and 1970 s there was great medical and political interest in screening for disease, with the hope that early detection would result in early treatment and cure, thus avoiding premature death and disability. Experience of work in South Wales and elsewhere suggested that the validation of screening procedures should be approached from two points of view. ${ }^{27}$ First "Is the test justified, scientifically and financially, by the resulting benefit to the community?" and second, "How efficient is the proposed test as a method of measurement?" In 1971, Cochrane and Holland judged that there may be some benefit for a small proportion of those screened, for tuberculosis, arterial blood pressure, blood sugar, iron 
deficiency anaemia in non-pregnant women, and intraocular pressure. In current practice, these conditions are usually checked by opportunistic screening, when visiting the general practitioner or optometrist. It is of interest to note that they judged that there was insufficient evidence to justify routine screening for carcinoma of the breast and cervix, both of which subsequently became national screening programmes, presumably because the screening tests were improved and the interventions judged beneficial.

\section{Summary}

This brief review has highlighted some of the research done by the MRC in the South Wales valleys. The two MRC Units published, in total, over 2000 reports ranging from letters to journals to conference proceedings, with around 200 reports appearing in the BMF, Lancet and Nature alone. The expertise gained in South Wales meant that the Pneumoconiosis Research Unit team was involved internationally in co-ordinating research on coal workers' lung disease, and later on the health effects of asbestos and other respirable dusts. It is remarkable that the early large-scale studies were conducted and analysed without the benefits of modern computers and statistical packages.

The varied Epidemiology Unit research programme enabled Cochrane to develop his ideas on defining health and evaluating health services, and also Elwood, who directed the Unit from 1974 to 1995, to pioneer studies of aspirin prophylaxis in cardiovascular disease. ${ }^{28} \mathrm{~A}$ steady stream of occupational health studies were carried out by

1 Hugh-Jones P, Fletcher CM. The social consequences of pneumoconiosis among coalminers in South Wales. MRC Memorandum No 25. London: HMSO, 1951. 2 D'Arcy Hart PD, Aslett EA. Medical Research Council Special Report. Ser No 243. London: HMSO, 1942

3 Cochrane AL. Effectiveness and efficiency: random reflections on health services. London: Nuffield Provincial Hospitals Trust, 1972.

4 Cochrane AL, Blythe M. One man's medicine: an autobiography of Professor Archie Cochrane. London: BMJ Memoir Club, 1989; pp 236-7.

5 Chalmers I, Sackett D, Silagy C. The Cochrane collaboration. In: Maynard A, Chalmers I (eds), Non-random reflections on health services research. London: BMJ/NPHT, 1997; pp 231-49.

6 Fletcher CM, Oldham PD. The problem of consistent radiological diagnosis in coalminers' pneumoconiosis. Br F Industr Med 1949;6:168-83.

7 Cochrane AL, Cox GJ, Jarman TF. Pulmonary tuberculosis in the Rhondda Fach. BMF 1952;ii:843-54

8 Atuhaire LK, Campbell MJ, Cochrane AL, Jones M, Moore F. Mortality of men in the Rhondda Fach 1950-1980. Br f Industr Med 1985;42:741-5.

9 Peto R, Speizer FE, Cochrane AL, et al. The relevance in adults of air-flow obstruction, but not of mucus hypersecretion, to mortality from chronic obstruction, but not of mucus hypersecretion, to
lung disease. Am Rev Respir Dis 1983;128:491-500.

10 Cotes JE. The open-circuit oxygen equipment used by the British Mount Everest Expedition. F Physiol 1953;123:24-5.

11 Cotes JE, Gilson JC. Effect of oxygen on exercise in chronic respiratory insufficiency - use of portable apparatus. Lancet 1956;i:872-6.

12 Miall WE, Caplan A, Cochrane AL, Kilpatrick GS, Oldham PD. An epidemiological study of rheumatoid arthritis associated with characteristic chest x-ray appearances in coal-workers. BMF 1953;ii:1231-7.

13 Wright BM, McKerrow CB. Maximum forced expiratory flow rate as a measure of ventilatory capacity - with a description of a new portable instrument for measuring it. BMF 1959;ii: 1041-7.

14 MRC Committee on the aetiology of chronic bronchitis. Definition and classification of chronic bronchitis for clinical and epidemiological purposes. Lancet 1965;i:775-9.

15 Miall WE, Oldham PD. A study of arterial blood pressure and its inheritance in a sample of the general population. Clin Sci 1955;14:459-88.

16 Miall WE, Oldham PD. Factors influencing arterial blood pressure in the general population. Clin Sci 1958;17:409-44.
Epidemiology Unit staff ${ }^{29}$ and many other large surveys were conducted in other parts of South Wales and across the country. Later MRC Epidemiology Unit work has focused on the town of Caerphilly where a prospective study of some 2500 men, established in 1979, has so far resulted in over 100 papers, notably on haemostatic factors related to heart disease. ${ }^{30}$ The study has run in tandem with a similar survey in the Speedwell area of Bristol which was established by former Epidemiology Unit staff working for the health authority in that area. ${ }^{30}$

Other medical research groups have also worked in the South Wales valleys. In 1961 Julian Tudor Hart left the Epidemiology Unit after a year's research to enter general practice, and establish the famous research practice at Glyncorrwg, over the mountain from the Rhondda Fawr. ${ }^{31}$

This year the extensive collection of MRC survey records is being transferred to the Department of Social Medicine at Bristol, and it is quite likely that further research will be undertaken relating Rhondda survey data collected over 40 years ago to subsequent mortality. The South Wales valleys will continue to contribute to medical research into the next millennium. Archie Cochrane's papers have been catalogued and are available for study at the Cochrane Archive established at Llandough Hospital.

HUGH F THOMAS MRC Epidemiology Unit, Llandough Hospital, Penarth, Vale of Glamorgan, CF64 2XW, UK

Accepted 14 January 1999

Keywords: Rhondda valleys; Medical Research Council

17 Oldham PD, Pickering G, Fraser Roberts JA, Sowry GSC. The nature of essential hypertension. Lancet 1960;1:1085-93.

18 Swales JD. Introduction. Hypertension: the past, the present and the future. In: Swales JD, ed. Textbook of hypertension. Oxford: Blackwell, 1994; pp 1-7.

19 Elwood PC, Jacobs A. Haemoglobin estimations: a comparison of different techniques. Br Med J 1966;1:20-24.

20 Elwood PC, Waters WE, Greene WJW, Sweetnam P, Wood MM. Symptoms and circulating haemoglobin level. J Chron Dis 1969;21:615-628.

21 Elwood PC, Waters WE, Sweetnam P. The haematinic effect of iron in flour. Clin Sci 1971;40:31-37.

22 Elwood PC, Waters WE, Benjamin IT, Sweetnam PM. Mortality and anaemia in women. Lancet $1974 ; \mathrm{i}: 891-894$.

23 Graham P, Hollows FC. Sources of variation in tonometry. Trans Ophthalmol Soc UK 1964;84:597-613.

24 Hollows FC, Graham P. Intra-ocular pressure, glaucoma and glaucoma suspects in a defined population. Br F Ophthalmol 1966;50:570-86.

25 Hollows FC, Corris P. Fred Hollows - the updated autobiography. Balmain NSW: Kerr Publishing, 1994.

26 Cochrane AL, Fletcher CM, Gilson JC, Hugh-Jones P. The role of periodic examination in the prevention of coalworkers pneumoconiosis. Br f Industr Med 1951;8:53-61.

27 Cochrane AL, Holland WW. Validation of screening procedures. $\mathrm{Br} \mathrm{Med}$ Bull 1971;27:3-8.

28 Elwood PC, Hughes C, O'Brien JR. Platelets, aspirin and cardiovascular disease. Postgrad Med f 1998;74:587-91.

29 Thomas HF. Three decades of occupational health research in South Wales. Occup Environ Med 1996;53:141-2.

30 The Caerphilly and Speedwell Collaboration Group. Caerphilly and Speedwell collaborative heart disease studies. F Epidemiol Commun Health 1984;38:259-62

31 Tudor Hart J, Davey Smith G. 1: Response rates in South Wales 1950-96: changing requirements for mass participation in human research. In: Maynard A, Chalmers I, eds, Non-random reflections on health services research. London: BMJ/NPHT 1997; pp 31-57. 